\title{
The relationship between attention deficit hyperactivity disorder and premature infants in Taiwanese: a case control study
}

\author{
Shih-Ming Chu ${ }^{1,5}$, Ming-Horng Tsai ${ }^{3,6}$, Fan-Ming Hwang ${ }^{2}$, Jen-Fu Hsu ${ }^{1,5}$, Hsuan Rong Huang ${ }^{1,5}$ \\ and Yu-Shu Huang ${ }^{4,5,7^{*}}$
}

\begin{abstract}
Background: Preterm survivors from the neonatal intensive care unit (NICU) are considered to be at risk for some neurobehavioral disorders such as attention-deficit/hyperactivity disorder (ADHD). The current study aimed to explore the relationship between ADHD and premature infants in Taiwan.

Methods: A total of 195 children (157 males and 38 females) diagnosed with ADHD based on DSM-IV and aged between 6 to 12 years and a control group of 212 (164 males, 48 females) age- and sex-matched healthy children were enrolled. The ADHD-Rating scale and CGl severity were performed by child psychiatrists. Demographic data of the children, including birth history, perinatal neurological and respiratory problems were collected to facilitate the investigation of whether a correlation exists between ADHD and prematurity.

Results: The ADHD group had a significantly higher rate of prematurity and significantly higher rate of low birth body weight (defined as $<2500 \mathrm{~g}$ ) than the control group (both $P=0.003$ ). Pearson correlation showed a significantly negative correlation between gestational age and ADHD-RS score, inattentive score, hyperactivity and CGI-S score ( $P=0.004,0.013,0.015$ and 0.002 , respectively). However, only a CGI-S score $(P=0.018)$ showed a significantly correlation between low birth weight and ADHD.

Conclusions: Premature infants have significantly more severe symptoms of ADHD at school age and they were highly correlated. Further study is necessary to determine the main effect and pathogenesis of moderate as well as extreme preterm birth on the development of ADHD.
\end{abstract}

Keywords: Premature infant, Attention-deficit/hyperactivity disorder, Behavioral disorder, DSM-IV, Gestational age

\section{Background}

Attention-deficit hyperactivity disorder (ADHD), a neurobehavioral syndrome characterized by inattention, impulsivity and hyperactivity, has been described for over a century as an unruly behavioral disorder most commonly seen in boys [1]. ADHD is noted in $3 \sim 9 \%$ of children and adolescents with a male-to-female ratio of 3:1 to $5: 1$ by previous publications [2-4] and $3-5 \%$ of adults with an equal male to female ratio based on the American Psychiatric Association's Diagnostic and Statistical

\footnotetext{
* Correspondence: hu1109s@yahoo.com.tw

${ }^{4}$ Department of Child Psychiatry and Sleep Center, Chang Gung Memorial Hospital, Taoyuan, Taiwan

${ }^{5}$ College of Medicine, Chang Gung University, Taoyuan, Taiwan

Full list of author information is available at the end of the article
}

Manual of Mental Disorders IV (DSM-IV) criteria [5-7]. The exact etiologies of ADHD have not been conclusively determined; however, lower brain volume or weight [8] and potential brain damage during perinatal insult of preterm birth [9] were proposed to be the possible reason of poor maturation of brain, which might result in development of ADHD during pre-school age.

There is growing interest in the mental health of premature infants, partly because their mortality rate has decreased over the last two decades $[10,11]$ and most of them survive without major physical disabilities. Very low birth weight infants (VLBW) are reported to be at increased risk of psychosocial [12-15] or behavioral problems [16]. In addition, VLBW children have a higher risk of perinatal white matter injury, which is associated

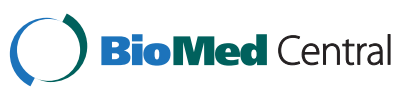


with perceptual, cognitive, motor and mental health impairment [17]. A recent study also suggested that moderately preterm children born at 32 to 36 weeks' gestational age specifically showed attention difficulties when compared with term-born children at school age [18]. An increase in the rates of preterm birth and low birth weight was found in both the United States and Asia $[19,20]$, and their long-term psychosocial impacts deserve further evaluations. The objective of this study was to analyze the relationship between ADHD and premature infants and the associations between severity of symptoms of ADHD and birth weight or gestational age.

\section{Methods}

\section{Subjects}

We reviewed the medical records of all children diagnosed with ADHD between January 2001 and December 2009 in the Department of Pediatric Psychiatry of Chang Gung Children's Hospital (CGMH), a tertiary-level university-affiliated teaching hospital in northern Taiwan. This study was approved by the institutional review board of CGMH. All patients were diagnosed by expert child psychiatrists and fulfilled the criteria of ADHD according to the 2000 DSM-IV-TR [21]. Children aged between 6 and 12 years old at the time of diagnosis of ADHD were recruited and studied in a regular education framework. We excluded children with an IQ of less than 70 on the WISC-III [22] and those with mental retardation, congenital anomalies, chromosome anomalies and/or neurological disorders.

A group of children involved in the study as the controls were recruited from the general community, and didn't have any major physical diseases, neurological problems, or psychiatric illnesses. We planned to enroll a group of age and sex-matched children to our ADHD group. An informed consent was obtained from their parents after well explanation. During this study period, 195 ADHD children (157 boys and 38 girls with M/F ratio of 4.1:1; mean age 8.8 years, SD 1.9, range 612 years) who were diagnosed based on DSM-IV-TR were enrolled. The control group consisted of 212 ageand sex-matched children (164 boys and 48 girls with M/F ratio of 3.4:1; mean age 9.1 years, SD: 3.9 ). There was no significant difference between the basic demographic data of the study and control groups (Table 1).

\section{Procedures}

An interview instrument of ADHD Rating Scale IV (ADHD-RS IV) [23], which is a rating scale that provides a reliable means of rating ADHD symptom severity for boys and girls aged 5-17 years old, was used by experienced child psychiatrists. A Clinical Global ImpressionSeverity (CGI-S) score was used to measure the symptom severity and treatment response of children with ADHD.
All birth history of the children in both the ADHD and control groups, including birth weight, gestational age, any perinatal insults, and respiratory or neurological complications were recorded from chart review and analyzed. A child was considered to have respiratory complication if he or she was admitted to the neonatal intensive care unit due to requirement of oxygen or ventilator support at birth.

\section{Statistical analysis}

We defined prematurity as a child who was delivered before 37 weeks' gestation and low birth body weight as $<2500 \mathrm{~g}$. The chi-square test and Fischer's exact test were used for categorical data, and comparisons of the continuous data between groups were performed by the student's $t$-test. Logistic regression was used to calculate odds ratios (ORs) and 95\% confidence intervals (CI) for risk of developing ADHD with prematurity and low birth weight. Multivariate logistic regression was performed to adjust for covariates of gender and age. Three kinds of model were tested by simple and multiple regressions. Model 1a, 1b, 1c, 1d analyze the effects of preterm on total score of ADHA, ADHD inattention score, ADHD hyperactivity score and CGI-S scores. Model 2a, 2b, 2c, 2d test the impacts of preterm and LBBW on total score of ADHA, ADHD inattention score, ADHD hyperactivity score and CGI-S scores. For Model 3a, 3b, 3c, 3d, gender and age were added into Model 2a, 2b, 2c, 2d as covariates to control the effects of these two variables. All statistics were performed using the commercially available software SPSS software for Windows (version 13.0; SPSS, Inc., Chicago, IL), and a $P$ value of less than 0.05 (two-tailed) was considered to be statistically significant.

\section{Results}

During the study period, a total of 195 children (157 males and 38 females) diagnosed with ADHD based on DSM-IV-TR were enrolled and completed the whole assessments. A control group of 212 age- and sexmatched children (164 males, 48 females) were recruited from the surrounding schools in the community. The demographic data, including birth history, are summarized in Table 1. The gestational age of the ADHD group and control group were $37.6 \pm 2.21$ (median: 38 , range: 27-43) weeks and $38.8 \pm 1.37$ (median: 38 ; range: $36-42$ ) weeks, respectively $(\mathrm{P}=0.08)$. Their mean birth body weight were $3007 \pm 563.5$ (median: 3015 ; range: 1700 4350 ) and $3351 \pm 417.5$ (median: 3250; range: 2500 4050) g, respectively $(\mathrm{P}=0.018)$. The ADHD group had significantly higher rate of prematurity and higher rate of low birth body weight than the control group (18.5\% vs. $8.5 \%$, and $15.8 \%$ vs. $6.6 \%$, both $P=0.003)$. The body mass index and rate of respiratory complications or 
Table 1 Demographic data of ADHD children versus controls

\begin{tabular}{|c|c|c|c|c|c|}
\hline & ADHD group & Control group & $P$ value & Odds ratio(C.I. $)^{(3)}$ & Odds ratio(C.I. $)^{(4)}$ \\
\hline Case number & 195 & 212 & & & \\
\hline Age $(y / o)($ mean $\pm S D)$ & $8.79 \pm 1.93$ & $9.13 \pm 3.87$ & $0.488^{(1)}$ & & \\
\hline Gender & & & $0.499^{(2)}$ & & \\
\hline Male, n (\%) & $157(80.5)$ & $164(77.3)$ & & & \\
\hline Female, n (\%) & $38(19.5)$ & $48(22.6)$ & & & \\
\hline Birth body weight, g (mean \pm SD) & $3007 \pm 563.5$ & $3351 \pm 417.5$ & $0.011^{(1)}$ & $0.999(0.998,1)$ & $0.999(0.998,1)$ \\
\hline Gestational age, weeks (mean \pm SD) & $37.6 \pm 2.21$ & $38.8 \pm 1.37$ & $0.005^{(1)}$ & $0.67(0.51,0.89)$ & $0.67(0.50,0.89)$ \\
\hline Prematurity*, n (\%) & $27(18.9)$ & $18(8.5)$ & $0.003^{(2)}$ & (5) & (5) \\
\hline Low birth body weight ${ }^{\top}, \mathrm{n}(\%)$ & $24(16.2)$ & $14(6.6)$ & $0.009^{(2)}$ & (5) & (5) \\
\hline Respiratory complications at birth, $\mathrm{n}(\%)$ & $5(2.6)$ & $2(0.9)$ & $0.336^{(2)}$ & & \\
\hline Neurological complications, n (\%) & $3(1.5)$ & $1(0.5)$ & $0.600^{(2)}$ & & \\
\hline Body mass index (pretest), $\mathrm{kg} / \mathrm{m}^{2}$ & $18.1 \pm 3.49$ & $18.72 \pm 3.67$ & $0.422^{(1)}$ & & \\
\hline \multicolumn{6}{|l|}{ ADHD Rating Scale IV } \\
\hline Total score $($ mean \pm SD) & $29.8 \pm 7.98$ & $10.73 \pm 2.81$ & $<0.001^{(1)}$ & & \\
\hline Inattention score (mean $\pm \mathrm{SD}$ ) & $16.9 \pm 4.23$ & $7.1 \pm 1.29$ & $<0.001^{(1)}$ & & \\
\hline Hyperactivity score (mean \pm SD) & $12.7 \pm 5.33$ & $4.17 \pm 1.78$ & $<0.001^{(1)}$ & & \\
\hline ADHD CGI-S (pretest) $($ mean \pm SD) & $4.5 \pm 0.91$ & $1.15 \pm 0.29$ & $<0.001^{(1)}$ & & \\
\hline
\end{tabular}

$A D H D$ attention-deficit/hyperactivity disorder; SD standard deviation; CGI-S Clinical Global Impression-Severity.

*Prematurity was defined as delivered before 37 weeks' gestation.

Low birth body weight was defined as $<2500 \mathrm{~g}$

(1): Independent samples $T$ test.

(2): Fisher's exact test.

(3): Odds ratio and confidence interval in logistic regression with ADHD as response and Birth body weight/Gestational age as the only predictor.

(4): Odds ratio and confidence interval in logistic regression, adjusted for gender and age.

(5): One of the cells in 2 by 2 table is equal to 0 , so we only present significance of Fisher's exact test.

neurological complications at birth were not significantly different between these two groups. The severity of ADHD symptoms, judged by ADHD-RS-IV and CGI-S scores, was significantly more severe in the ADHD group than the control group (all $P<0.001$ ).

Table 2 presents The ADHD symptoms severity by Influences of various factors (Preterm birth and low birth body weight). From Table 2, we could find that when children with preterm birth was only one predictor in regression, it had significant effects on total score of ADHA, ADHD inattention score, ADHD hyperactivity score and CGI-S scores $(\beta=0.218, \quad p<0.01, \quad \beta=0.189$, $\mathrm{p}<0.05, \quad \beta=0.167, \mathrm{p}<0.05, \beta=0.233, \mathrm{p}<0.01$, respectively)(See model 1a, 1b, 1c, 1d). When adding LBBW

Table 2 The ADHD symptoms severity by Influences of various factors (Preterm birth and low birth body weight)

\begin{tabular}{|c|c|c|c|c|c|c|c|c|c|c|c|c|}
\hline & Model 1a & Model 2a & Model 3a & Model 1b & Model $2 b$ & Model 3b & Model 1c & Model 2c & Model 3c & Model 1d & Model 2d & Model 3d \\
\hline & \multicolumn{3}{|c|}{ ADHD Total score } & \multicolumn{3}{|c|}{ Inattention score } & \multicolumn{3}{|c|}{ Hyperactivity score } & \multicolumn{3}{|c|}{ ADHD CGI-S } \\
\hline Preterm & $0.218^{* *}$ & $0.218^{*}$ & $0.194^{*}$ & $0.189^{*}$ & 0.167 & 0.153 & $0.167^{*}$ & 0.178 & 0.148 & $0.233^{* *}$ & $0.201^{*}$ & $0.181^{*}$ \\
\hline LBBW & & -0.003 & 0.002 & & 0.037 & 0.041 & & -0.023 & -0.015 & & 0.051 & 0.057 \\
\hline Gender & & & -0.131 & & & -0.078 & & & $-0.165^{*}$ & & & -0.107 \\
\hline age & & & -0.137 & & & -0.077 & & & $-0.162^{*}$ & & & -0.131 \\
\hline F-value & $7.943^{* *}$ & $3.847^{*}$ & $3.506^{* *}$ & $5.899^{*}$ & 2.924 & 1.95 & $4.570^{*}$ & 2.234 & $3.434^{*}$ & $9.436^{* *}$ & $4.73^{*}$ & $3.676^{* *}$ \\
\hline Adj. $R^{\wedge} 2$ & 0.042 & 0.047 & 0.059 & 0.030 & 0.024 & 0.02 & 0.022 & 0.015 & 0.058 & 0.048 & 0.043 & 0.061 \\
\hline
\end{tabular}

*: p-value $<0.05 ;{ }^{* *}$ : p-value $<0.01$.

$A D H D$ attention-deficit/hyperactivity disorder.

CGI-S Clinical Global Impression-Severity.

Preterm: indicator variable ("Gestational age $<37$ weeks" $=1$; otherwise $=0$ ).

LBBW: indicator variable ("Birth body weight $<2500 \mathrm{~g}$ " $=1$; otherwise $=0$ ).

Gender: control variable ("male" =0; "female" $=1$ ).

Age: control variable.

F-value: $F$ statistics of ANOVA.

$\operatorname{Adj} . R^{\wedge} 2$ adjusted R-squared. 
into regression, it still had significant effects on total score of ADHA and CGI-S scores, but the effects on ADHD inattention score, ADHD hyperactivity score became not significant(See Model 2a, 2b, 2c, 2d). For LBBW, it had no significant effects on all scores and the $\beta$ s were far lower that those of children with preterm birth. This result indicated that children with preterm birth had larger influence on the ADHD symptoms severity. When gender and gestational age were also put into regressions as control variables, the results were similar to the second model (Model 2a, 2b, 2c, 2d).

Table 3 showed the Pearson correlation performed for evaluation if ADHD symptoms severity is associated with preterm birth or birth body weight. Gestational age was noted to be negatively correlated with severity of ADHD symptoms, and all parameters, including ADHD RS total score, inattention or hyperactivity scores and ADHD CGI-S scores, were found to reach a significant level of less than 0.05 . Birth body weight was noted to be negatively correlated with ADHD CGI-S score (Pearson correlation, $\mathrm{r}=-0.181, P=0.018$ ), but was not significantly correlated with hyperactivity score. Moreover, a lower birth body weight was also found to correlate with a higher ADHD RS total $(\mathrm{P}=0.057)$ and inattention $(\mathrm{P}=0.053)$.

\section{Discussion}

Our study found that the ADHD group has a relatively higher rate of prematurity and a significantly higher rate of low birth body weight than the general population. We also demonstrated that both moderate preterm birth (gestational age between 33 weeks to 37 weeks) and low

Table 3 The associations of ADHD symptoms severity and birth body weight and gestational age evaluated by Pearson correlations

\begin{tabular}{lcc}
\hline Pearson correlation & $\begin{array}{c}\text { Gestational } \\
\text { age (weeks) }\end{array}$ & $\begin{array}{c}\text { Birth body } \\
\text { weight (g) }\end{array}$ \\
\hline ADHD RS total score & -0.225 & -0.149 \\
$r$ & $0.004^{* *}$ & 0.057 \\
p & & -0.152 \\
ADHD inattention score & -0.195 & 0.053 \\
$r$ & $0.013^{*}$ & \\
p & & -0.115 \\
ADHD hyperactivity score & -0.192 & 0.143 \\
$r$ & $0.015^{*}$ & -0.181 \\
p & & $0.018^{* *}$ \\
ADHD CGl-S (pretest) & -0.237 & \\
$r$ & $0.002^{* *}$ & \\
p & & \\
\hline
\end{tabular}

$A D H D$ attention-deficit/hyperactivity disorder. CGI-S Clinical Global Impression-Severity. birth body weight (defined as birth body weight $<2500 \mathrm{~g}$ ) are associated with more severe ADHD symptoms. Previous studies have concluded that very preterm children were reported to exhibit significantly more behavioral problems and cognitive disorders [16,24]; however, most of these studies focused on very preterm $(\leq 33$ weeks' gestation) and extremely very low birth body weight [24-27]. Our data support recent literature with regard to the observation that inattention and emotional regulation difficulties affect the functioning of moderate preterm children at school age [18].

The significant association between ADHD and preterm birth or low birth body weight can be explained by several mechanisms. First, some of the children suffered from intrauterine growth retardation and their less matured brain structure due to suboptimal fetal environment; these conditions may be associated with postnatal illness and later development of ADHD [28]. Second, less favorable parent-child or family interaction with children during the first half-year of preterm or SGA (small for gestational age) [29] may affect the neurobehavioral development of these children. Furthermore, the underlying causes of premature birth, either genetic or environment factors, may also influence or interfere with normal neuronal development and organizations, which may contribute to subsequent ADHD symptoms [30].

Another interesting finding of our study was that the more severe ADHD symptoms, including inattention, hyperactivity and impulsivity, were significantly correlated with more preterm birth or lower gestational age. However, lower birth body weight was only associated with inattention, but not hyperactivity or impulsivity. To our knowledge, our study was the only one to conclude both low birth body weight and preterm birth as independent risk factors for the development of ADHD at school age. These two factors may not be correlated, because in studies of low-birth-weight $(<2500 \mathrm{~g})$ but term-born children, small body size at birth predicts behavioral symptoms of ADHD [28,31]. These findings can be partially explained by the theory that inattention was correlated with cognition and hyperactivity or impulsivity was correlated with poor inhibition of movement. Low gestational age could affect both neurological cognition and control of movement, while birth body weight might only affect cognition. This theory deserves further prospective design with larger sample to confirm this theory.

Previous studies have demonstrated an increased risk for ADHD in follow-up studies of preterm survivors from NICUs [32-34]. Even in moderately preterm children, cognitive and emotional regulation difficulties affect their functioning at school age, and a slightly lower IQ with attention and behavioral problems are found when they are compared with term-born children 
[35,36]. In these studies, inattention problems are found in $15-25 \%$ of the moderately preterm-born children and approximately one-third of very preterm children at their school age [32-36]. In addition, preterm birth carries some risk for psychiatric disorders requiring hospitalization in adolescence and young adults [33,37], thus the requirement of more attention in research and secondary prevention is warranted.

A major limitation of our study is its relatively small sample size and retrospective design. We are unable to further extend our conclusion to very low birth body weight children $(<$ or $=1500 \mathrm{~g})$ and very preterm children ( $<$ or $=32$ weeks' gestation). However, our study had excluded the cases of well-defined brain damage such as intraventricular hemorrhage, periventricular leukomalacia, or cerebral palsy from perinatal asphyxia. We also excluded children with an IQ of less than 70 on the WISC-III, and those with major mental, neurological, or physical disease, which may have resulted in the exclusion of very low birth body weight and very preterm infants from our study sample. Furthermore, our study applied ADHD questionnaires from parents and teachers rather than utilizing objective measurements of quality of life, person-to-person relationships, academic achievements, or neurocognitive tests. A further well-designed, prospective study is required to confirm our findings.

It is our hope that, by gaining a better understanding of the strong relationships between preterm birth, low birth body weight and the risk of developing ADHD, many undefined efforts can be progressed to avoid preterm birth. Further attention should be paid to these children by having child psychiatric clinics perform regular follow-ups to track their behavioral and emotional conditions.

\section{Conclusion}

Children with ADHD have a significantly higher rate of prematurity and low birth body weight. The severity of ADHD symptoms, including ADHD RS total score, inattention or hyperactivity scores and ADHD CGI-S scores, are highly correlated with extent of prematurity. Premature brain, less favorable postnatal condition and illness of preterm neonates, or poor parent-child interaction may contribute interactively to their suboptimal neurobehavioral development and subsequent ADHD, but the underlying pathogenesis remains uninvestigated and deserves further studies.

\section{Competing interests}

The authors declare that they have no competing interests.

\section{Authors' contributions}

S-MC Carried out the study and wrote the manuscript. M-HT collected the data; assumed the role of attending physician of the premature neonates. J-FH Responsible for editing the English version of the study; assumed the role of attending physician of the premature neonates. F-MH performed the statistical analysis. $\mathrm{H}-\mathrm{RH}$ the attending physician of our premature neonates. Y-SH the corresponding author, overview and supervise the whole study and writing of manuscript. All authors read and approved the final manuscript.

\section{Author details}

'Division of Pediatric Neonatology, Department of Pediatrics, Chang Gung Memorial Hospital, Taoyuan, Taiwan. ${ }^{2}$ Department of Education, National Chia-Yi University, Chiayi, Taiwan. ${ }^{3}$ Division of Pediatric Neonatology and Hematology/Oncology, Chang Gung Memorial Hospital, Yunlin, Taiwan. ${ }^{4}$ Department of Child Psychiatry and Sleep Center, Chang Gung Memorial Hospital, Taoyuan, Taiwan. ${ }^{5}$ College of Medicine, Chang Gung University, Taoyuan, Taiwan. ${ }^{6}$ Chang Gung Institute of Technology, Chiayi, Taiwan. ${ }^{7}$ Department of Child Psychiatry and Sleep Center, Chang Gung Memorial Hospital, 5, Fu-Shing St., Kwei-Shan, Taoyuan 333, Taiwan.

Received: 8 June 2011 Accepted: 23 July 2012

Published: 23 July 2012

\section{References}

1. Still G: The Coulstonian lectures on some abnormal physical conditions in children. Lecture 1. Lancet 1902, 1008-1112(1077-1902):1163-1168.

2. Froehlich TE, Lanphear BP, Epstein JN, et al: Prevalence, recognition, and treatment of attention-deficit/hyperactivity disorder in a national sample of US children. Arch Pediatr Adolesc Med 2007, 161:857-864.

3. Skounti M, Philalithis A, Galanakis E: Variations in prevalence of attention deficit hyperactivity disorder worldwide. Eur J Pediatr 2007, 16:430-438.

4. Shear K, Jin R, Ruscio AM: Prevalence and correlates of estimated DSM-IV child and adult separation anxiety disorder in the National Comorbidity Survey Replication. Am J Psychiatry 2006, 163:1074-1083.

5. Faraone SV, Sergeant J, Gillberg C, et al: The worldwide prevalence of ADHD: is it an American condition? World Psychiatry 2003, 2:104-113.

6. Kessler RC, Adler L, Barkley R, et al: The prevalence and correlates of adult ADHD in the United States: results from the National Comorbidity Survey Replication. Am J Psychiatry 2006, 163:716-723.

7. Wilens TE, Spencer TJ, Biederman J: A review of pharmacotherapy of adults with attention-deficit hyperactivity disorder. J Atten Dis 2002, 5:189-202.

8. Kinney HC: The near-term (late preterm) human brain and risk for periventricular leukomalacia: a review. Semin Perinatal 2006, 30:81-88.

9. Skrablin S, Maurac I, Banovic V, et al: Perinatal factors associated with the neurologic impairment of children born preterm. Int J Gynaecol Obstet 2008, 102:12-18.

10. Fanaroff $A A$, Stoll BJ, Wright $L L$, et al: Treads in neonatal morbidity and mortality for very low birthweight infants. Am J Obstet Gynecol 2007, 196:147-148.

11. Peters $\mathrm{KL}$, Rosychuk RJ, Hendson $\mathrm{L}$, et al: Improvement of short- and longterm outcomes for very low birth weight infants: Edmonton NIDCAP trial. Pediatrics 2009, 124:1090-1020.

12. Bhutta AT, Cleves MA, Casey PH, et al: Cognitive and behavioral outcomes of school-aged children who were born preterm: a meta-analysis. JAMA 2002, 288:728-737.

13. Hack M, Youngstrom EA, Cartar $L$, et al: Behavioral outcomes and evidence of psychopathology among very low birth weight infants at age 20 years. Pediatrics 2004, 114:932-940.

14. Saigal S, Doyle LW: An overview of mortality and sequelae of preterm birth from infancy to adulthood. Lancet 2008, 371:261-269.

15. Saigal S, Pinelli J, Hoult $L$, et al: Psychopathology and social competencies of adolescents who were extremely low birth weight. Pediatrics 2003, 111:969-975.

16. Delobel-Ayoub M, Arnaud C, White-Koning M, et al: Behavioral problems and cognitive performance at 5 years of age after very preterm birth: the EPIPAGE study. Pediatrics 2009, 123:1485-1492.

17. Skranes J, Vangberg TR, Kulseng S, et al: Clinical findings and white matter abnormalities seen on diffusion tensor imaging in adolescents with very low birth weight. Brain 2007, 130:654-666.

18. van Baar AL, Vermaas J, Knots $E$, et al: Functioning at school age of moderately preterm children born at 32 to 36 weeks' gestational age. Pediatrics 2009, 124:251-257.

19. Davidoff MJ, Dias T, Damus K, et al: Changes in the gestational age distribution among U.S. singleton births: impact on rates of late preterm birth, 1992 to 2002. Semin Perinatol 2006, 30:8-15. 
20. Goldenberg RL, Culhane JF, lams JD: Epidemiology and causes of preterm birth. Lancet 2008, 371:75-84

21. American Psychiatric Association: Diagnostic and Statistical Manual of Mental Disorders. 4th edition. Washington DC: American Psychiatric Association; 2000:85-93.

22. Wechsler D: Manual for the Wechsler Intelligence Scale for Children, (Chinese Version). 3rd edition. San Antonia: The Psychological Corporation; 1991

23. DuPaul Gl, Anastopoulos AD, Power TJ, et al: Parent ratings of attentiondeficit/hyperactivity disorder symptoms: factor structure and normative data. J Psychopathol Behav Assess 1998, 20:83-102.

24. Espirito Santo JL, Portuguez MW, Nunes ML: Cognitive and behavioral status of low birth weight preterm children raised in a developing country at preschool age. J Pediatr 2009, 85:35-41.

25. Aarnoudse-Moens CS, Weisglas-Kuperus N, van Goudoever JB, et al: Metaanalysis of neurobehavioral outcomes in very preterm and/or very low birth weight children. Pediatrics 2009, 124:717-728.

26. Johnson S: Cognitive and behavioral outcomes following very preterm birth. Semin Fetal Neonatal Med 2007, 12:363-373.

27. Strang-Karisson S, Raikkonen K, Pesonen AK, et al: Very low birth weight and behavioral symptoms of attention deficit hyperactivity disorder in young adulthood: the Helsinki study of very-low-birth-weight adults. Am J Psychiatry 2008, 165:1345-1353.

28. Lahti J, Raikkonen K: Kajantie E et al: Small body size at birth and behavioral symptoms of ADHD in children aged five to six years. J Child Psychol Psychiatry 2006, 47:1167-1174.

29. Feldman R: Maternal versus child risk and the development of parentchild and family relationships in five high-risk populations. Dev Psychopathol 2007, 19:293-312.

30. McLaughlin KA, Fox NA, Zeanah CH, et al: Delayed maturation in brain electrical activity partially explains the association between early environmental deprivation and symptoms of attention-deficit /hyperactivity disorder. Biol Psychiatry 2010, 68:329-336.

31. Mick E, Biederman J, Prince J, et al: Impact of low birth weight on attention-deficit hyperactivity disorder. J Dev Behav Pediatr 2002, 23:16-22.

32. Lindström $\mathrm{K}$, Lindblad $\mathrm{F}$, Hjern A: Preterm birth and attention-deficit /hyperactivity disorder in schoolchildren. Pediatrics 2011, 127:858-865.

33. Lindström K, Lindblad F, Hjern A: Psychiatric morbidity in adolescents and young adults born preterm: a Swedish national cohort study. Pediatrics 2009, 123:e47-e53.

34. Aarnoudse-Moens CS, Weisglas-Kuperus N, van Goudoever JB, Oosteriaan J: Meta-analysis of neurobehavioral outcomes in very preterm and/or very low birth weight children. Pediatrics 2009, 124:717-728.

35. van Baar AL, Vermaas J, Knots E, de Kleine MJ, Soons P: Functioning at school age of moderately preterm children born at 32 to 36 weeks' gestational age. Pediatrics 2009, 124:251-257.

36. Bhutta AT, Cleves MA, Casey PH, Cradock MM, Anand KJ: Cognitive and behavioral outcomes of school-aged children who were born preterm: a meta-analysis. JAMA 2002, 288:728-737.

37. Selling KE, Carstensen J, Finnströrn O, Josefsson A, Sydsjö G Hospitalizations in adolescence and early adulthood among Swedish men and women born preterm or small for gestational age. Epidemiology 2008, 19:63-70

doi:10.1186/1471-244X-12-85

Cite this article as: Chu et al:: The relationship between attention deficit hyperactivity disorder and premature infants in Taiwanese: a case control study. BMC Psychiatry 2012 12:85.

\section{Submit your next manuscript to BioMed Central and take full advantage of:}

- Convenient online submission

- Thorough peer review

- No space constraints or color figure charges

- Immediate publication on acceptance

- Inclusion in PubMed, CAS, Scopus and Google Scholar

- Research which is freely available for redistribution

Submit your manuscript at www.biomedcentral.com/submit
Biomed Central 